\title{
MODELO DE GESTÃO DA EDUCAÇÃO SUPERIOR PRIVADA BRASILEIRA ${ }^{i}$
}

\author{
MANAGEMENT MODEL OF PRIVATE BRAZILIAN HIGHER EDUCATION
}

\section{MODELO DE GESTIÓN DE LA EDUCACIÓN SUPERIOR PRIVADA DE BRASIL}

\section{RESUMO}

\author{
Claudia Mara Stapani Ruas ${ }^{1}$ \\ Regina Tereza Cestari Oliveira ${ }^{2}$
}

Este artigo aborda um segmento específico da educação superior, o setor privado com fins lucrativos, focando o Grupo Anhanguera Educacional. O objetivo deste artigo é analisar o modelo de gestão dessa instituição de educação superior a partir da abertura de suas ações na BM\&F Bovespa, em 2007, até se tornar o maior oligopólio educacional, em 2012, da América Latina. Dados documentais, estatísticos e entrevista apresentam as exigências e as estratégias para a inserção e permanência lucrativa no mercado de capitais, desse Grupo. Ressalta, ainda, a adoção de um modelo de gestão gerencial oligopólico, com a dominância do capital financeiro, guiado por estratégias racionalizadora, reducionista, otimizadora e padronizadora, indicando como tendência a monopolização do setor, pelo próprio movimento de fusão e aquisição (F\&A) observado no mercado da educação superior privada com fins lucrativos.

PALAVRAS-CHAVE: Educação superior privada com fins lucrativos. Fusão e Aquisição. Oligopólios. Modelo de gestão da educação superior. Grupo Anhanguera Educacional.

\begin{abstract}
This paper analyses a particular segment of the higher education, the private sector, for profit, having as parameter the Anhanguera Educational Group. The objective of this article is to analyze the management model adopted by Anhanguera Group after opening for profit at the business market (BM\&F Bovespa) in March 2007. Furthermore, in 2012, this group became the largest educational oligopoly in Latin America. Documentary, statistical and interview data present the requirements and strategies needed for insertion and profitable stay in the capital market. This research also emphasizes the adoption of a model of oligopoly managerial management, with the dominance of finance capital. Understanding the private higher education, with profit, the results of this article ratified an oligopolistic management based a reductionist rational strategy, optimizer and patterned, pointing as tendency the sector monopolization, by the own flow of the process of buying-selling-merger described in this paper.
\end{abstract}

KEYWORDS: Private for profit higher education. Buying-selling-merger. Oligopolies. Higher education management model. Anhanguera Educational.

\footnotetext{
${ }^{1}$ Doutora em Educação pela Universidade Católica Dom Bosco de Campo Grande/MS. Docente nos Cursos de Comunicação Social da Universidade Católica Dom Bosco. E-mail: claudia@ ucdb.br - ORCID: http://orcid.org/0000-0001-8793-2078

${ }^{2}$ Doutora em Educação pela UNICAMP. Docente no Programa de Pós-Graduação em Educação da Universidade Católica Dom Bosco. E-mail: reginacestari@ucdb.br

Submetido em: 14/10/2016 - Aceito em: 24/11/2016
} 


\begin{abstract}
RESUMEN
Este artículo se dirige a un segmento específico de la educación superior, el sector privado con fines de lucro, centrándose en el Grupo Anhanguera. El objetivo de este artículo es analizar el modelo de gestión de esta institución de educación superior (IES) a partir de la apertura de sus acciones en la BM\&F Bovespa en 2007 para convertirse en el más grande oligopolio educativa en 2012 en América Latina. Datos documentales, estadísticos y entrevistas presentan los requisitos y estrategias para la entrada y estancia rentable en el mercado de capitales del grupo. También hace la adopción de un modelo de gestión empresarial oligopolio, con el predominio del capital financiero, dirigido por estrategias de racionalización, reduccionista, optimizadora y normalizadora, señalando como una tendencia a monopolizar el sector, por el movimiento de fusiones $\mathrm{y}$ adquisiciones (M\&A) observada en el mercado de la educación superior privada con fines de lucro.
\end{abstract}

PALABRAS CLAVE: Educación superior privada con fines de lucro. Fusão y adquisición. Oligopolios Modelo de gestión de la educación superior. Anhanguera Grupo Educativo.

\title{
Introdução
}

Este estudo analisa um segmento específico da educação superior brasileiro: o privado com fins lucrativos. Busca-se analisar o modelo de gestão adotado pelas Instituições de Educação Superior (IES), focando o Grupo Anhanguera Educacional, em função de suas particularidades, como ter sido pioneira na abertura dos serviços educacionais na BM\&FBovespa, em março de 2007; ter sido líder em fusões e aquisições e ser a maior IES privada com fins lucrativos, da América Latina (CHAVES, 2010). O procedimento metodológico utilizado consta de pesquisa exploratória, com levantamento dos documentos produzidos pelo Grupo Anhanguera, bibliografia em livros, artigos, revistas especializadas e jornais diários de grande circulação. Baseado em leituras e análises desse material, o trabalho foi formatado em duas partes. Na primeira abordou-se o setor privado mercantil e a nova configuração da expansão da educação superior privada com a oligopolização do setor. Esse processo de formação dos grandes oligopólios no cenário educacional brasileiro deve-se pela liberalização e desregulamentação do setor privado, após a aprovação da Lei de Diretrizes e Bases da Educação Nacional, Lei n. 9.394 de 1996. A constituição dos oligopólios ocorreu após 2007, quando foi aberto o capital das IES na bolsa de valores, permitindo a entrada de novos players no negócio, dando início ao processo de fusão e aquisição (F\&A) de IES brasileiras. $\mathrm{Na}$ segunda parte descreveram-se as exigências e as estratégias adotadas pelo Grupo Anhanguera para sua inserção e permanência lucrativa no mercado de capitais. As IES, atuando em um mercado altamente competitivo, precisaram adotar um modelo de gestão gerencial, com foco em resultados, para vencer a concorrência e garantir resultados aos seus acionistas. Dessa forma, suas estratégias foram direcionadas, prioritariamente, visando lucro, com uma submissão total ao mercado.

Por fim, conclui-se que a partir da entrada do Grupo Anhanguera na BM\&FBovespa, em 2007, comprovou-se o fenômeno da oligopolização do setor. Este foi o caminho percorrido pela Anhanguera, investindo maciçamente no setor educacional, por meio de F\&A, por ser um mercado promissor e altamente lucrativo. Seu crescimento exponencial no mercado brasileiro deveu-se à implementação de uma gestão oligopólica, guiada por estratégias racionalizadora, reducionista, otimizadora e padronizada, para atender às demandas do capital financeiro. Essas estratégias facilitaram e agilizaram o processo de F\&A das IES, apontando como tendência, a

\begin{tabular}{l|l|l|l|l|l|l} 
(C) Rev. Inter. Educ. Sup. & Campinas, SP & v.2 & n.3 & p. 461-479 & set./dez. 2016 & ISSN 2446-9424
\end{tabular}


monopolização da educação superior privada mercantil. 


\section{Formação de Oligopólios: Uma Nova Face da Privatização da Educação Superior}

Na segunda metade do século XX, o sistema capitalista brasileiro fortaleceu-se, notadamente na educação superior, que começou a ser encarado pela lógica mercantil e privatista. Tal processo iniciou-se na década de 1960, quando novas regras foram estabelecidas pelas Leis de Diretrizes e Bases LDB (1961), pela Reforma Universitária (1968) e pela Reforma do Ensino de $1^{\circ}$ e $2^{\circ}$ graus (1971). Orientaram estas reformas os acordos MEC-Usaid ${ }^{3}$ (Ministério da Educação e Cultura e United States Agency for International Development), na mencionada década. A partir desse acordo o Brasil recebeu apoio técnico e financeiro para implementar novas reformas e atrelar o sistema educacional brasileiro ao modelo econômico dos americanos. Este apoio provocou uma expansão quantitativa do segmento, até a chegada das IES no mercado de ações. Nesse sentido, segundo Polizel e Steinberg (2013) quem quiser sobreviver nesse mercado altamente competitivo, como vem se tornando o da educação superior, terá que ser eficaz não só no ensino, como também na condução do negócio educação. Portanto, faz-se necessária a busca de novas oportunidades de mercado para manter o crescimento, tanto quantitativo quanto lucrativo, das IES privadas brasileiras. Assim, segundo Stephan (2011, p. 364) "[...] entre os anos de 1991 e 2000 o número de IES passou de 893 para 1.180. Uma década depois esse número quase triplicou, sendo de aproximadamente três mil IES em 2010”.

Esse cenário concorrencial teve início com a reestruturação da educação superior, durante o governo Fernando Henrique Cardoso (1994-2002), com institucionalização da Lei de Diretrizes e Bases da Educação Nacional (LDBEN) 9394/96, uma vez que esta lei “[...] possibilitou um novo ordenamento jurídico para a educação e introduziu inúmeras modificações no campo da educação superior" (FERREIRA, 2012, p. 459), possibilitando a alteração de IES sem fins lucrativos em instituições de cunho lucrativo, voltadas ao mercado.

Dessa forma, o cenário da educação superior foi modificado, no Brasil, e passou a ser considerado como "[...] um vasto supermercado. As escolas e inclusive os nossos alunos tornam-se mercadorias que são compradas e vendidas do mesmo modo como se compram e vendem outro gênero de mercadorias" (APPLE, 2005, p. 18).

Tal contexto foi intensificado a partir da entrada das IES na BM\&F Bovespa ${ }^{4}$, inaugurando o segmento de serviços educacionais, iniciando o movimento de F\&A, com o

\footnotetext{
${ }^{3}$ Os acordos visavam a estabelecer convênios de assistência técnica e cooperação financeira à educação brasileira. Entre junho de 1964 e janeiro de 1968, período de maior intensidade nos acordos, foram firmados 12, abrangendo desde a educação primária (atual ensino fundamental) ao ensino superior. $\mathrm{O}$ último dos acordos firmados foi no ano de 1976 (MINTO, 2012).

${ }^{4} \mathrm{BM} \& \mathrm{~F}$ Bovespa ou Bolsa de Valores pode ser definida como um mercado organizado em que ativos financeiros, como ações, derivativos e instrumentos de renda fixa são negociados por membro destas instituições, normalmente, corretoras de valores. [...] Em 2008, a Bolsa de Valores de São Paulo (BOVESPA) era a bolsa oficial do Brasil, até iniciar um processo de fusão com a Bolsa de Mercadorias e Futuros (BM\&F)
} \begin{tabular}{l|l|l|l|l|l|l} 
(C) Rev. Inter. Educ. Sup. & Campinas, SP & v.2 & n.3 & p. 461-479 & set./dez. 2016 & ISSN 2446-9424
\end{tabular} 
objetivo de angariar vantagens, tais como: “[...] economia de escala; maior controle de custos, fruto de uma gestão profissional; menores valores de mensalidade, reflexo da redução de custos; maior potencial de recursos para investimentos e acesso a capital de baixo custo" (POLIZEL; STEINBERG, 2013, p. 11).

Empresas educacionais como Anhanguera, Estácio de Sá, Kroton Educacional, do Grupo Pitágoras de Minas Gerais, e a Sociedade Educacional Brasileira (SEB), controladora do Colégio Oswaldo Cruz (COC), do interior de São Paulo, abriram seu capital na bolsa de valores. A partir de 2007, deu-se início ao movimento de F\&A fomentado pela entrada do capital financeiro internacional no segmento educacional brasileiro. A partir desse movimento deu-se a formação dos oligopólios entendidos, nesse estudo, como formas muito concentrada de produção e de comercialização em escala internacional "[...] de empresas nacionais e internacionais de ensino superior" (CHAVES, 2010, p. 481).

A gênese desse processo ocorreu em 2001, quando um grupo de Minas Gerais fechou parceria com a Apollo Internacional $l^{5}$, parceria que durou até 2006, quando o grupo mineiro comprou a parte do investidor internacional. Essa parceria, de caráter transnacional, foi um dos primeiros sinais da penetração do capital financeiro. Entretanto, Oliveira (2009, p. 744) acredita que o marco "[...] foi deflagrado a partir de duas transações comerciais. A primeira refere-se à aquisição, em dezembro de 2005, da Universidade Anhembi Morumbi, pelo grupo americano Laureate e a segunda o caso Anhanguera". Nesse período, conforme matéria veiculada na Gazeta Mercantil ${ }^{6}$ concretizou-se a venda de $51 \%^{7}$ da Universidade Anhembi Morumbi para o Laureate International. "O valor do investimento foi de US\$ 69 milhões e o grupo que a adquiriu deve anunciar mais três aquisições em distintos pontos do País. De acordo com os planos do Laureate, $100 \%$ das ações da Anhembi Morumbi serão adquiridas pelos americanos até 2013 ”.

O panorama educacional transformou-se, a partir daí, segundo Bittar (2002, p. 54) “[...] em um vale tudo nesse nível de ensino. A educação superior transformou-se num grande supermercado, em cujas prateleiras produtos e serviços disputam a atenção e o desejo dos consumidores". Esse cenário foi consolidado com a dominância do capital, principalmente o financeiro, provocando o fenômeno da oligopolização da Educação Superior.

que culminou na criação de uma nova instituição, denominada BM\&F Bovespa no dia 8 de maio de 2008 (BM\&F BOVESPA, 2009).

5 O Grupo Apollo adaptou para a faculdade Pitágoras a metodologia da inovadora Universidade de Phoenix, EUA. Disponível em: <http://www.faculdadepitagoras.com.br/conheca/parceiros.asp>. Acesso em: 14 jan. 2012.

${ }^{6}$ Título da matéria: "Universidade privada acirra disputa aluno por aluno", veiculada em 27/11/2007. Disponível em: <http://avaliacaodeempresas.blogspot.com/2007/11/educao-privada-no-brasil.html>. Acesso em: 14 jan. 2012.

${ }^{7}$ Em 30 de janeiro de 2013 foi anunciada a compra de mais 49\% da UAM, por meio de seu fundo americano de private equity KKR, tornando a Laureate agora a única proprietária. Para acelerar a expansão em países emergentes, a Laureate recebeu um aporte de US\$ 150 milhões da International Finance Corporation (IFC), braço financeiro do BM. Disponível em: <http://economia.estadao.com. br/noticias/geral,laureate-fica-com-100da-anhembi-morumbi-imp-,990673>. Acesso em: 7 nov. 2014.

\begin{tabular}{l|l|l|l} 
(C) Rev. Inter. Educ. Sup. & Campinas, SP & v.2 & n.3
\end{tabular}

p. $461-479$

set./dez. 2016

ISSN 2446-9424 
O pioneirismo do Grupo Anhanguera, na BM\&F Bovespa, proporcionou uma alta lucratividade em sua primeira Oferta Pública Inicial (IPO - Initial Public Offering) ${ }^{8}$ sigla em inglês para Oferta Pública Inicial. Em sua primeira IPO, o Grupo captou a quantia de R \$ 360 milhões, valor utilizado para dar início aos planos do Grupo, ou seja, "[...] fortalecer as unidades, acelerar a execução da estratégia de expansão, aprimorar o modelo de negócio, visando sempre atender a um número cada vez maior de jovens trabalhadores em todo o país" (ANHANGUERA. RDF, 2008, p. 3). Em sua primeira oferta, o Grupo “[...] emitiu, vendeu novas ações e canalizou para si todos os recursos auferidos. De acordo com a Bovespa, a Cia amplia o seu quadro de sócios, com os compradores das ações" (PEQUENO; MORAIS, 2010, p. 233).

Sob o código de Ativo AEDU11, em 17 de março de 2007, o Grupo passou a ter como principais investidores "[...] os fundos de investimentos, fundos de pensão e fundos de aposentadoria e poucos bancos" (CARBONARI NETTO, Entrevista, 2014), além de pelo menos "[...] 15 mil CPFs que adquiriram ações da Anhanguera, dentre eles professores, alunos e funcionários. Além disso, de 80 a 100 fundos internacionais acreditaram no projeto" (CARBONARI NETTO, 2008, s./p.).

Com os valores obtidos em sua segunda IPO - Initial Public Offering ${ }^{9}$ da bolsa, em outubro, o Grupo fez outra grande aquisição, adquirindo a sua primeira universidade:

A Universidade Regional do Pantanal de Campo Grande/MS e mais cinco instituições do Grupo Pedro Chaves Santos Filho, de Mato Grosso do Sul. As Faculdades Integradas de Ponta Porã, Faculdades Dourados, Instituto de Ensino Superior de Dourados, Centro Universitário de Campo Grande e as Faculdades Integradas de Rio Verde, por R\$246,8 milhões (OLIVEIRA, 2009, p. 746).

Estas aquisições tornaram a Anhanguera, de acordo com Chaves (2010, p. 492-493), "[...] empresa líder em aquisições e fusões de IES, ocupando atualmente a posição de destaque no setor". A vice-liderança é ocupada pela Estácio de Sá. Esse foi o resultado "da mudança de um modelo familiar e filantrópico para outro, com objetivos lucrativos e tendo que prestar contas ao mercado" 10 .

\footnotetext{
${ }^{8}$ Segundo Veiga (2007) "a oferta pública de ações é o ato de possibilitar a qualquer pessoa a oportunidade de adquirir uma participação em uma determinada empresa. A oferta pública inicial ocorre quando se está querendo 'abrir' o capital da empresa".

9 Segundo Veiga (2007) "a oferta pública de ações é o ato de possibilitar a qualquer pessoa a oportunidade de adquirir uma participação em uma determinada empresa. A oferta pública inicial ocorre quando se está querendo 'abrir' o capital da empresa”. Simplificando: supõe-se a existência de uma empresa, na qual há um único proprietário, em expansão. Com o tempo, ao invés de recorrer a empréstimos para crescimento (além dos lucros gerados pela empresa para o aumento do capital), consideram-se novos sócios. Para colocar em prática tal decisão, o capital da empresa pode ser aberto, possibilitando a entrada de outros investidores interessados na oferta pública inicial. Assim, os mesmos participarão como sócios da empresa, ao comprarem as ações à venda.

${ }^{10}$ Matéria veiculada em 25 de agosto de 2008 - Grupos educacionais lançam ações na Bolsa e crescem $67 \%$ de Antônio Góis, no Jornal Folha de São Paulo. Disponível em: <http:www1.folha.uol.com.br/folha/educação/ult 304u437468.shtml>. Acesso em: 22 dez. 2011.

\begin{tabular}{l|l|l|l|l|l|l} 
(C) Rev. Inter. Educ. Sup. & Campinas, SP & v.2 & n.3 & p. 461-479 & set./dez. 2016 & ISSN 2446-9424
\end{tabular}
}


Nesse cenário, a educação superior passou a ser um negócio altamente rentável, principalmente pela valorização das ações. De 2007 a 2012 papéis das principais IES privadas tiveram altas de até 150\% (CM Consultoria, 2013). No entanto, somente em 2012, as ações da Anhanguera valorizaram "[...] 72\%, sendo que no mesmo período o Ibovespa acumulava apenas 7,4\% de alta no ano" (ANHANGUERA. RRS, 2012, p. 55).

Esse movimento, segundo Braga (2011, p. 15), presidente da Consultoria Hoper SA, ainda tem muito espaço para crescer, pois "[...] grupos consolidadores, juntos, possuem também quase um bilhão de reais. Os fundos de private equity interessados em educação têm capacidade de investimento no setor na ordem de 1,2 bilhões de reais".

Esses grupos favoreceram o processo de F\&A de IES de menores portes, bem como foram os responsáveis pela formação de quatro grupos atuantes no Brasil. Na composição desses grupos encontram-se grandes bancos de investimentos nacionais, como o Grupo Pátria, sócio do grupo Anhanguera, e fundos de investimentos internacionais, como o Grupo americano Laureate, proprietário, desde 2013, da Universidade Anhembi Morumbi.

Esses grupos passaram a fazer parte do sistema de educação superior brasileira mercantil e estão conquistando o mercado de forma cada vez mais incisiva, principalmente porque são gerenciados por administradores profissionais. Esses profissionais trazem das empresas de mercado estratégias que propiciam, ao negócio da educação, um aumento significativo em seus lucros, o que têm incentivado o crescimento no número de transações no Brasil. Dados da consultoria $\mathrm{KPMG}^{11}$ apontam que o Brasil "[...] é o terceiro maior país em números de fusões e aquisições no setor educacional do mundo e as empresas de educação despontam como um dos setores que deve apresentar forte valorização na bolsa".

Nesse contexto, está inserido o Grupo Anhanguera, que se submeteu às regras do mercado, e para atender as novas demandas do capital passou a introduzir uma gestão cuja forma está claramente pautada em um modelo de gestão orientado para o mercado. Esse modelo foi responsável por transformar o Grupo em uma das maiores IES, em termos de número de alunos, da América Latina, bem como, tornar-se atrativa para aquisição, em 2013, pelo Grupo Kroton. Ressalta-se que, até 2010, o Grupo Kroton era tido como um dos menores grupos do setor, com um faturamento inferior à metade da líder e um valor de mercado $20 \%$ abaixo da primeira colocada no ranking dos oligopólios, a Anhanguera (CM Consultoria, 2014).

$\mathrm{Na}$ busca desenfreada para crescer e ganhar mercado, o Brasil assistiu, com esse fato, ao início de um novo ciclo: o das grandes fusões, com a participação direta de agentes do

\footnotetext{
${ }^{11}$ A KPMG opera como uma rede internacional de firmas-membro que oferecem serviços de Audit, Tax e Advisory. Oferecemos um conjunto consistente de habilidades e competências contábeis e financeiras fundamentadas no profundo conhecimento do segmento de mercado de cada cliente. No Brasil, somos aproximadamente 4.000 profissionais distribuídos em 12 Estados e Distrito Federal e 20 cidades. Disponível em: <http://www.kpmg.com.br>. Acesso em: 14 jan. 2012.

\begin{tabular}{l|l|l|l|l|l|l} 
(C) Rev. Inter. Educ. Sup. & Campinas, SP & v.2 & n.3 & p. 461-479 & set./dez. 2016 & ISSN 2446-9424
\end{tabular}
} 
setor financeiro. A Anhanguera, maior empresa do país em faturamento e número de alunos e a Kroton, maior empresa de ensino universitário do mundo em valor de mercado, à frente da Chinesa New Oriental, fundiram-se por meio de uma troca de ações estimada em 5 bilhões de reais. Coube à Kroton 57,48\% das ações e 42,52\% à Anhanguera (ISTO É DINHEIRO, 2013). Surgiu, assim, a maior companhia de ensino privado do país, a maior empresa da América Latina e uma das maiores empresas educacionais mercantis do mundo, com valor de mercado próximo a 12 bilhões, abocanhando $15 \%$ de todos os alunos do Brasil.

\section{MODELO DE GESTÃO DO GRUPO ANHANGUERA}

Uma gestão orientada para o mercado atendendo ao capital financeiro foi adotada por todos os oligopólios da educação superior, no Brasil, principalmente pelo Grupo Anhanguera. Implementada por profissionais oriundos de empresas do mercado, bem como por consultorias contratadas para elaborar planos estratégicos, essa gestão garantiu às IES um aumento significativo em seus lucros.

Para Colombo (2004), a gestão é um processo mais amplo do que administrar. Além de planejar, organizar, controlar e avaliar, conceitos já intrínsecos à administração, agora também abrange a busca pela inovação e melhorias de processos, identificando as oportunidades do mercado, minimizando as ameaças e potencializando sua competitividade, elemento chave que impulsiona as IES às novas práticas quanto à gestão.

Dessa forma, a gestão do Grupo Anhanguera, identificando como oportunidade o mercado de capitais, começou a estruturar-se bem antes de 2007, conforme assevera Carbonari Netto, em entrevista a Polizel e Steinberg (2013, p. 66):

[...] durante os três anos $(2004,2005,2006)$ foi iniciado um processo de reestruturação em nossa instituição, acompanhado pela criação de quatro comitês: administração, marketing, finanças e expansão. Nos cinco anos decorrentes da implantação da estrutura da Governança Corporativa $(\mathrm{GC})^{12}$ tomaram-se algumas decisões e ações: a primeira foi profissionalizar a gestão; a segunda, desfamiliarizar a estrutura de gestão, e a ideia agora é a inovação de produtos, novos mercados e novos futuros.

Essa estrutura de GC foi introduzida no meio empresarial, na década de 1990, fruto da necessidade das IES em se adaptarem às exigências e padrões internacionais para atrair investidores. Para as empresas que desejavam entrar e permanecer no mercado de capitais a exigência era utilizar algum nível de GC para garantia de transparência nos negócios. A GC

12 Governança corporativa é o sistema pelo qual as organizações são dirigidas, monitoradas e incentivadas, envolvendo os relacionamentos entre proprietário, Conselho de Administração, Diretoria e órgãos de controle. As boas práticas de governança corporativa convertem princípios em recomendações objetivas, alinhando interesses com a finalidade de preservar e otimizar o valor da organização, facilitando seu acesso a recursos e contribuindo para sua longevidade (IBGC, 2012, p. 19).

\begin{tabular}{l|l|l|l|l|l|l} 
(C) Rev. Inter. Educ. Sup. & Campinas, SP & v.2 & n.3 & p. 461-479 & set./dez. 2016 & ISSN 2446-9424
\end{tabular}


passou, então, a fazer parte do seu cotidiano, como fruto das necessidades destas IES em inserirem-se nos padrões internacionais e atrair o maior número possível de investidores.

Desde então, empresas de todos os segmentos, inclusive o educacional, precisaram dar atenção especial à qualidade da administração, baseando-se em princípios "[...] de transparência, de ética e eficiência, bem como equidade de tratamento justo a todos os acionistas (minoritários e majoritários) e prestação de contas de sua atuação, assumindo integralmente as consequências de seus atos e omissões" (CVM, 2008, s/p). Para atender as exigências do mercado regulatório brasileiro, as IES privadas, com fins lucrativos, profissionalizaram a gestão assumindo práticas de GC. Essas práticas reforçavam a necessidade, do Grupo, em se debruçar sobre sua estrutura de poder, buscando separar o contexto empresarial do familiar, para atrair mais investimentos. Para isso, segundo Polizel e Steinberg (2013) não há necessidade de haver uma ruptura entre o negócio e a família, apenas uma mudança de pensamento em relação à gestão do negócio.

No Brasil, as empresas passaram a inserir práticas da GC, principalmente pela necessidade de atrair capital e fontes de financiamento para ampliar suas atividades empresariais, como foi o caso da Anhanguera. Precisando aderir à GC, a partir de 2006, o Grupo investiu em condutas que aumentaram a transparência da gestão e a comunicação com os acionistas, a fim de ter o retorno esperado na investida sobre o mercado. Os benefícios alcançados foram:

Maior facilidade de acesso a recursos externos, diretamente ligados a um menor custo de capital, um melhor desempenho organizacional, a facilitação na dissolução de conflitos, por vezes de maneira mais amigável e a minoração de riscos empresariais (POLIZEL; STEINBERG, 2013, p. 23).

Para potencializar a valorização das suas ações, o Grupo seguiu estritamente o disposto nas leis brasileiras, regularizando tributos, observando a necessidade de atendimento às normas mais específicas e rigorosas no que tange aos procedimentos e princípios contábeis, de auditoria e divulgação de demonstrativos financeiros. Também foi observada a criação da figura do Diretor de Relações com o Investidor ${ }^{13}$, que compartilha com seus investidores, informações claras, sobre as atividades e resultados do Grupo, aumentando a confiança e, consequentemente, fortalecendo a imagem institucional (CVM, 2008).

Carbonari Netto (2008) assevera que os gestores da Anhanguera precisaram focar na elaboração de um planejamento estratégico, uma vez que as "[...] tarefas centrais desse planejamento é identificar e aproveitar oportunidades do mercado antes dos concorrentes" (BRAGA; MONTEIRO, 2005, p. 93). Esse planejamento, no intuito de capacitar as empresas, torna-se imprescindível, pois são suas estratégias que geram ações, para

\footnotetext{
${ }^{13}$ Em 2007, quando a Anhanguera entrou no mercado de capitais, o Diretor de Relações com o Investidor era Ricardo Scavazza. A partir de 31 de outubro de 2011 o cargo foi assumido por José Augusto Gonçalves de Araújo Teixeira, que também passou a acumular o cargo de Vice-Presidente Financeiro (ANHANGUERA. Informações anuais - data base - 31/12/2008).

\begin{tabular}{|c|c|c|c|c|c|c}
\hline C Rev. Inter. Educ. Sup. & Campinas, SP & v.2 & n.3 & p. 461-479 & set./dez. 2016 & ISSN 2446-9424 \\
\hline
\end{tabular}
}


economizar, crescer e lucrar, fatores indispensáveis para a manutenção e sobrevivência do negócio.

Assim, o Grupo Anhanguera procurou moldar sua gestão para atingir o objetivo de tornar-se, até 2012, a maior instituição de ensino superior do Brasil e a primeira opção em educação superior particular para a nova classe média brasileira em todos os mercados onde atua (ANHANGUERA. RRS, 2012, p. 14). Para isso precisou contemplar uma definição dos produtos (cursos e modalidades), preço, estratégia de localização e inovação em benefícios e vantagens. Essas estratégias planejadas concretizaram-se mediante uma gestão atenta ao mercado e às suas exigências, que tinha diante de si um novo cenário decorrente do aumento da oferta. Isto é, um número cada vez maior de IES disputando alunos quase que individualmente, emergindo a necessidade de aprimorar uma das mais importantes áreas do conhecimento para conhecer, captar, lidar e fidelizar clientes: o marketing. Ter uma gestão de marketing eficaz é sinal de competitividade. Essa mesma competitividade que vem impulsionando os gestores do setor privado à "[...] busca permanente de introduzir nas IES os métodos e formas gerenciais concorrentes no mundo empresarial não-educacional" (RODRIGUES, 2007, p. 22).

De acordo com Braga e Monteiro (2005, p. 13), essa busca se fez imprescindível pela necessidade de "[...] baixar custos para continuar a ser competitivo e, ao mesmo tempo, reinventar-se na captação e na fidelização de alunos, de forma a permitir um crescimento contínuo e sustentado”.

Para chegar a resultados que tornaram o Grupo Anhanguera um gigante do setor foi necessário implementar algumas estratégias reducionistas, para auferir maior rentabilidade ao Grupo. Essa estratégia foi a utilização de $20 \%$ da carga horária dos cursos, com atividades não presenciais. A adoção deste modelo foi responsável pela maior redução de custos, em função da diminuição nos gastos com a folha de pagamento, pois eximia do pagamento do adicional noturno aos docentes, conforme Oliveira (2009, p.744), esclarece:

[...] Essa estratégia, além de trazer uma redução na hora/aula em sala com a presença do professor, também reduziu o pagamento de hora-aula aos professores, pois no período noturno, após às $22 \mathrm{~h}$, os professores devem, por lei, receber um adicional noturno, entretanto, com essa estratégia os alunos, no terceiro tempo de aula, são encaminhados para outras atividades em laboratório, bibliotecas ou são simplesmente dispensados.

Essa estratégia condiz com o discurso de Carbonari Netto et al. (2012, p.41), posto que, na sua visão a educação "[...] passou a ser encarada como uma indústria como outra qualquer, ou seja, um mercado de compra e venda do conhecimento. Neste mercado, somente vendendo, ele cresce e seu proprietário lucra".

Dando continuidade à sua gestão para se tornar, cada vez mais, competitiva, o Grupo Anhanguera procurava oferecer mensalidades inferiores às da concorrência. Sobre o assunto, 
Mautone (2007, s./p.) afirma que "[...] os valores cobrados nas mensalidades são entre $20 \%$ e $50 \%$ mais baixos que os das concorrentes".

A oferta de cursos basicamente noturnos coadunava-se com o perfil do alunado a ser atendido e foi um fator estrategicamente estipulado pela empresa, decorrente da averiguação de que "[...] a maioria dos alunos trabalhava durante o dia. Assim, o ponto forte do Anhanguera deveria ser o oferecimento de cursos noturnos" (CARBONARI NETTO, 2008).

Para o Grupo, fatores como mais alunos em suas unidades, mensalidades com valores mais baixos e cursos compatíveis com a realidade salarial dos estudantes, contribuíram para a diluição de custos indiretos e ganho de escala, otimizando sua gestão para ter excelência nos processos.

As ações implementadas pelo Grupo que foram sendo oferecidas à classe trabalhadora, como a estratégia de preço e cursos noturnos, somou-se a outra iniciativa adotada pela Anhanguera: localização de suas unidades. Mautone (2007, s./p.) afirma que:

A Anhanguera contrata empresas especializadas em mapear a população de determinada região levando em conta dados como: nível de renda, faixa etária e escolaridade, uma metodologia adotada por companhias como Carrefour, WalMart, McDonald's. Só depois dessas análises demográficas detalhadas, que costumam resultar em calhamaços de mais de 100 páginas, a rede decide em qual bairro abrirá uma nova unidade. Em São Paulo, onde a Anhanguera começou a operar, já foram identificados dez pontos viáveis para a instalação de novas escolas. Todos eles estão localizados na periferia, para a população de baixa renda. É importante que as faculdades fiquem perto do trabalho ou de casa, de modo que ela possa economizar o dinheiro do transporte. Economias como essa são fundamentais para que os alunos mantenham a capacidade de pagar as mensalidades

A localização dos campi, segundo Mautone (2007) é considerada pelos estudantes do Grupo o segundo atrativo mais importante para a tomada de decisão de onde estudar. Em primeiro lugar os alunos, certamente, apontam para a questão de preço da mensalidade como um fator definitivo para sua decisão. Sobre o posicionamento da Anhanguera, no quesito preço, tal estratégia a tornou reconhecida, no mercado, como as "Casas Bahia da Educação" (MAUTONE, 2007, s./p.). Carbonari Netto (2008a, s./p.) argumenta:

[...] Sempre ouvimos muitas críticas ao nosso modelo de ensino. Mas isso não me aborrece. Uma reportagem da revista EXAME se referiu às nossas faculdades como Casas Bahia da educação. Senti-me muito honrado. Afinal, as Casas Bahia são referência mundial em eficiência e inovação.

Para o Grupo, são as estratégias adotadas que viabilizaram seu crescimento e contribuíram para a matrícula de uma parcela emergente ao ensino superior, facilitando seu acesso em função de cursos com preços mais baixos, localização de seus campi que, por serem próximos às suas residências e de seus trabalhos, demandam, aos alunos, menos tempo e menos investimento em transporte. 
Estratégias reducionistas e otimizadoras para ganho de escala e barateamento de custos foram complementadas por estratégias padronizadoras como a instalação do Programa de Livro-Texto (PLT), considerado programa pioneiro na educação superior. Este programa oferece aos alunos, a preço de custo, livros reconhecidos no cenário nacional e internacional (ANHANGUERA. RRS, 2008). Ainda segundo o Grupo, o PLT proporciona aos alunos a oportunidade de adquirir, a cada semestre, livros que serão utilizados em seu curso. Fechar parcerias com editoras e contratar especialistas para produção de conteúdos, são ações que, como as demais, foram implementadas ao longo dos anos em suas unidades. Ações estas, cruciais para o desempenho e a diferenciação dos produtos do Grupo Anhanguera frente ao mercado e à concorrência.

Outra estratégia para maximizar lucros e captar cada vez mais alunos, pois segundo Las Casas (2008) é essa a premissa básica para a sobrevivência de uma IES, foi a profissionalização da gestão de Marketing (ANHANGUERA, 2014). A crença no potencial do marketing e em suas ferramentas como propaganda, promoção, marketing digital entre outras, foi um fator determinante para a criação de uma vice-presidência da área e que trouxe do mercado, em abril de 2011, Roberto Valério". "Sua missão no Grupo é reforçar o posicionamento da marca, além de fortalecer as plataformas digitais e o relacionamento com o aluno" (MEIO \& MENSAGEM, 2011).

O executivo citado teve como tarefa prioritária criar um conceito que estreitasse o seu relacionamento com os alunos. Criou-se a assinatura do Grupo, procurando atender a esse novo posicionamento que cumpria as propostas de ensino da Anhanguera que, junto com a UNIBAN, formaram a maior instituição de ensino superior do Brasil (ANHANGUERA, 2011, s./p.).

Dando continuidade à política de trazer profissionais do mercado para o Grupo e pôr em prática o objetivo de trabalhar a área de novas tecnologias, foi contratado Alexandre Dias, ex-presidente da Google Brasil. Considerado um dos principais executivos do mercado, esse profissional assumiu o cargo de executivo-chefe da Anhanguera com a missão de agregar aos cursos inovações tecnológicas, especialmente aquelas relacionadas ao ensino a distância. Em entrevista, Alexandre Dias afirmou que foi contratado pelo Grupo Anhanguera com a finalidade de

[...] elevar a qualidade e a penetração do ensino superior oferecido, focando no grande mercado que é as classes ' $\mathrm{C}$ e D'. Alinhando o conhecimento tecnológico que adquiriu na Google à gestão do Grupo, terá como um dos principais desafios

\footnotetext{
${ }^{14}$ Roberto Valério é graduado em Administração de Empresas pela FGV, pós-graduado em business administration pela mesma instituição e especialização em marketing e relações com consumidores pela americana Columbia University. Atuou em companhias de mídia, acumula passagens pela DirectTV, onde atuou entre 2005 a 2010, na base da empresa em Nova Iorque, como diretor de marketing. Valério não pensava em voltar para o Brasil, mas foi motivado pelo desafio de profissionalizar o grupo com 13 mil funcionários. 'Fui seduzido pelo enorme potencial da marca e pelo ambiente econômico propício. Era uma oportunidade única (HAUSSER, 2012).
}

\begin{tabular}{l|l|l|l|l|l|l} 
(C) Rev. Inter. Educ. Sup. & Campinas, SP & v.2 & n.3 & p. 461-479 & set./dez. 2016 & ISSN 2446-9424
\end{tabular}


tornar os cursos mais acessíveis, disponibilizando um melhor ensino a distância (SETTI, 2010, s./p.).

Desta forma, a Anhanguera passou a investir em tecnologia. Segundo Roberto Valério, Diretor-Presidente do Grupo, este "[...] é um ponto forte da gestão do grupo: investimento em tecnologia, [...] iniciativa suportada por uma governança cada vez mais atuante" (ANHANGUERA. RRS, 2013, p. 7). Assim, procurando aproximar-se de seu público-alvo, o Grupo investiu no marketing digital, principalmente fazendo uso das redes sociais

[...] para manter comunicação com seus alunos, potenciais estudantes e comunidade em geral, conforme a característica de cada rede social Facebook, Twitter, Youtube, Linkedin e Google+. Essas estratégias de marketing, além de fortalecerem a marca no ambiente digital, têm como uma das principais finalidades atrair novos talentos para a instituição (ANHANGUERA. RRS, 2013, s./p.).

Além de utilizar ferramentas que os alunos acessam diariamente, também foram criadas plataformas, estabelecendo parcerias, para otimizar e agilizar o relacionamento online entre alunos e professores, como Google Apps, bem como facilitar a colocação de seu acadêmico no mercado de trabalho, como é o caso da parceria com a Catho.

Hausser (2012, p. 13) afirma que a Catho é “[...] um site de classificados de currículos e vagas de emprego de maior audiência da América Latina”, e que para se cadastrar o aluno não desembolsa nenhum valor, é gratuito. De acordo com o Relatório de Responsabilidade Social (ANHANGUERA. RRS, 2012), a Catho permite contato com mais de 265 mil vagas anunciadas, acesso a dicas de aperfeiçoamento, orientações para elaboração de currículo e preparação para entrevistas, dentre outras, sendo a assinatura de duração semestral, renovável automaticamente. Para o Grupo, essa parceria é uma forma de mostrar ao aluno que a instituição está cumprindo seu papel de facilitadora entre a academia e o mercado.

No contexto financeiro do Grupo coube ao marketing, enquanto instrumental de gestão, encontrar uma estratégia para solucionar o problema daqueles alunos que não podem ou não conseguem arcar com o valor das mensalidades. Assim, em 2012, o marketing do Grupo sugeriu a criação de uma entidade financiadora, nos moldes do sistema bancário existente no mercado. Para reduzir a incidência da inadimplência, o banco do Grupo Anhanguera, segundo Foitinho (2012, s./p.) implantou o sistema, de modo não somente a apertar as negociações com os maus pagadores, mas também flexibilizá-las com os bons alunos, que puderam, a partir de então, financiar em até 16 vezes seu curso ou trocá-lo por outro, de preço mais acessível. Essa estratégia foi implementada quando a taxa de inadimplência na instituição atingia os $10 \%$. Dessa forma, decidiu-se operar como financeira, parcelando a dívida do aluno.

Outro setor criado pelo Grupo para facilitar o acesso à informação, pelo aluno, foi o Serviço de Apoio ao Estudante (SAE) que faz um atendimento especializado e pessoal e existe em todas as unidades da Anhanguera. Por seu intermédio, o estudante recebe

\begin{tabular}{l|l|l|l|l|l|l} 
(C) Rev. Inter. Educ. Sup. & Campinas, SP & v.2 & n.3 & p. 461-479 & set./dez. 2016 & ISSN 2446-9424 \\
\hline
\end{tabular}


orientação e é encaminhado para resolver dúvidas ou problemas pedagógicos, acadêmicos e financeiros, no intuito de manter o aluno satisfeito desde seu ingresso no Grupo até a conclusão do seu curso. Monitora, constantemente, as suas demandas, por meio da elaboração do projeto "Programa de Acompanhamento Acadêmico para Permanência do Estudante".

Para ser uma das maiores IES do mundo, ao longo dos últimos seis anos de atuação do Grupo, desde sua entrada na BM\&FBovespa até ser adquirida pelo grupo Kroton, a Anhanguera precisou adequar, constantemente, sua gestão frente às necessidades e expectativas do mercado, "[...] sempre se antecipando à concorrência, garantindo sua liderança e hegemonia no negócio da educação superior privada brasileira" (ANHANGUERA. RDF, 2007, p. 8).

O modelo de gestao gerencial oligopólico adotado pelo Grupo transformaram a Anhanguera no maior oligopólio do Brasil e "[...] o segundo do mundo no segmento, em número de alunos, perdendo apenas para o Apollo, dos EUA, controladora da Universidade de Phoenix nos Estados Unidos." (ETHOS, 2011). Com esse desempenho, o Grupo Anhanguera tornou-se atrativo para o fundo de investimento estrangeiro, o Advent, principal acionista da Kroton Educacional, sendo adquirido em abril de 2013, dando início às megafusões no Brasil. Segundo a CM Consultoria, em entrevista a Silva (2012), o Brasil não mais assistirá a maior IES comprar a menor, mas os grandes grupos comprando outros maiores. Nota-se, assim, uma tendência monopólica.

Até o ano de 2010, o Brasil possuía quatro grandes oligopólios: Anhanguera (líder), Estácio (vice), SEB e Kroton. Essa equação se modificou quando o grupo SEB foi comprado por um grupo britânico Pearson e deixou de ter suas ações negociadas na Bolsa. No final de 2010, restavam no mercado de capitais apenas três grandes grupos. Em abril de 2013, após a megafusão entre a Kroton e a Anhanguera, restaram, a partir de então, no mercado da educação superior brasileira apenas dois grandes oligopólios: Kroton e Estácio, abocanhando $20 \%$ de todo alunado brasileiro.

Ao longo dos seus seis anos de atuação, de 2007 a 2012, o Grupo Anhanguera tornouse altamente lucrativo para seus investidores. Primeiramente pela profissionalização da gestão adotando a GC como uma exigência para entrar no mercado de capitais, e depois investindo em sua gestão administrativa, aqui entendida como a articuladora das estratégias que impulsionaram a excelentes resultados econômico-financeiros. Após sua inserção no processo de F\&A, no final de 2007, o Grupo contava com mais de 92 mil alunos matriculados em suas unidades, um número mais de três vezes superior ao de dezembro de 2006, e lucro líquido quatro vezes superior ao de 2006, atingindo R\$ 63,5 milhões (ANHANGUERA. RDF, 2007, p. 10). 
Com a implementação de um modelo de gestão, com foco em resultados, procurando cada vez mais aumentar a lucratividade do Grupo, a implementação de suas estratégias, para manter sua inserção no mercado de forma lucrativa para seus investidores, nacionais e internacionais, foram decisivas. Foram estratégias que propiciaram aos investidores a garantia de seus lucros, mas também angariaram novos investidores que constataram a alta atratividade do setor pela valorização, cada vez maior, das ações do Grupo.

\section{Considerações Finais}

A partir da compreensão do cenário da educação superior privada com fins lucrativos, da sua abertura de capital no mercado de ações, em 2007, entende-se como se constituem os grandes oligopólios da educação superior brasileira. Trata-se de um avanço que parece ser impossível frear, pois esses oligopólios ocupam um espaço em que imperam as leis do mercado, no qual o lucro auferido deve ser apenas um meio pelo qual se possam aprimorar os processos e não um fim em si mesmo.

O processo mercantil na educação superior foi intensificado pelo aumento da competitividade no setor e pelo novo perfil da expansão da educação superior brasileira, com a entrada no negócio educacional de novos players, os grandes fundos de investimentos nacionais e estrangeiros. Esses players exigiram das IES a adoção de um modelo de gestão, pois, segundo Gramani (2008, p. 441) "[...] uma IES deve estar sempre objetivando maior atratividade, buscando maior rentabilidade, otimizando seus recursos e aumentando os investimentos em si própria”. Diante desse cenário e da necessidade de obtenção do lucro, a qualquer preço, e sem uma regulação e controle efetivo do Estado, assistiu-se a um cenário com a total subordinação da educação superior privada, com fins lucrativos, ao capital financeiro.

Esse mesmo capital impulsionou também consequências no trabalho docente que, inseridos no modelo de gestão gerencial oligopólico, tem seu regime de contratação basicamente horistas, invibializando o investimento em atividades de pesquisa, posto que esses docentes são pagos por hora-aula. Esse fato pode induzi-los a circular entre várias IES para sobreviver, exercendo sua atividade profissional. Esse cenário não se coaduna com a atividade de pesquisa, nem com a produção de conhecimento novo para transmissão à comunidade acadêmica, ao contrário, coloca em xeque a qualidade do ensino. Entretanto, para atender a demada do capital financeiro, esse regime promove a economia no pagamento dos docentes, prática que permite o oferecimento de mensalidades mais baratas, tornando seus cursos atrativos.

Pelos fatos apresentados neste estudo estamos diante da transformação do saber em mercadoria, com as IES privadas com fins lucrativos atendendo à pressão do modelo capitalista neoliberal, regido pela busca incessante do lucro. Esse foi o caminho percorrido

\begin{tabular}{l|l|l|l|l|l|l|} 
(C) Rev. Inter. Educ. Sup. & Campinas, SP & v.2 & n.3 & p. 461-479 & set./dez. 2016 & ISSN 2446-9424 \\
\hline
\end{tabular}


pelas políticas institucionais do Grupo Anhanguera, sempre regidas com intuito de agregar valor ao capital e encontraram, na adoção de um modelo de gestão gerencial oligopólico, não apenas mais transparência nas ações, como também maior lucratividade para o negócio, por meio de estratégias racionalizadoras, reducionistas, otimizadores e padronizadas.

O Grupo Anhanguera passou a ditar normas para o mercado de educação superior privada com fins lucrativos, com altos investimentos em tecnologia, marketing e propaganda para captação de alunos, e não deixando espaço para o surgimento de outras IES, instituindose características monopólicas no setor. Observa-se, dessa forma, a clara tendência à monopolização, diante do que se apresenta entre as IES privadas com fins lucrativos em função da sua concentração, ferindo princípios da livre concorrência. Esse mesmo princípio que diminui a cada movimentação de F\&A, no mercado educacional brasileiro.

\section{Referências}

APPLE, Michael W. Para além da lógica do mercado: compreendendo e opondo-se ao neoliberalismo. São Paulo: DP\&A Editora, 2005.

ANHANGUERA. Relações com investidores. Notícias, 12 março, 2007. Disponível em: <http://http//www.mzweb.com.br/anhanguera2011/web/mobile/conteudo_mobile.asp?idioma $=0 \&$ tipo $=39310 \&$ conta $=28 \&$ id $=145694>$. Acesso em: 27 jul. 2013 .

ANHANGUERA. Anhanguera reporta crescimento de $\mathbf{1 2 5 , 8 \%}$ na Receita Líquida e de 243,8\% no Lucro Líquido Ajustado no $1^{\circ}$ Trimestre de 2007. Valinhos 2007a. Disponível em:

<http://www.mzweb.com.br/kroton2010/web/arquivos/ananhanguera_er_1t07_20070517_por t.pdf $>$. Acesso em: 14 ago. 2014.

ANHANGUERA.RDF 2007. Demonstrações Financeiras em 31 de dezembro de 2006 e 2005. Valinhos, 2007. Disponível em:

<http://www.mzweb.com.br/kroton2010/web/arquivos/Anhanguera_DF_2006_20091208_po rt.pdf>. Acesso em: 29 set. 2014.

ANHANGUERA. RDF 2008. Demonstrações Financeiras em 31 de dezembro de 2007 e 2006. Valinhos, 30 de março de 2008. Disponível em: <http://www.mzweb.com.br/kroton2010/web/arquivos/NAHANGUERA_DF_20080213_port .pdf>. Acesso em: 10 maio 2013.

ANHANGUERA. Estatuto social da Anhanguera Educacional Participações S.A. 2011. Disponível em: <http://www.mzweb.com.br/anhanguera2011/web/arquivos/AEDU11_Estatuto_Social_ 20110708_PORT.pdf>. Acesso em: 10 jun. 2014.

ANHANGUERA. RRS 2012. Relatório de Responsabilidade Social 2012. São Paulo, Valinhos, 2012. 
ANHANGUERA. RRS 2013. Relatório de Responsabilidade Social 2013. São Paulo, Valinhos, 2013.

ANHANGUERA. Relações com os Investidores. Histórico/2014. Disponível em: <http://www.mzweb.com.br/anhanguera2011/web/conteudo_pt.asp?idioma=0\&conta=28\&tip o=39269>. Acesso em: 27 jul. 2014.

BRAGA, Ryon. Ensino superior: perspectivas para 2011. Linha direta: inovação, educação, gestão. Belo Horizonte: Ed. 155, ano 14, p. 12-16, fev., 2011.

BITTAR, Mariluce. Educação Superior - o "vale tudo" na mercantilização do ensino. Quaestio. Sorocaba: UNISO, v. 1, n² 2, p. 51-64, 2002.

BRAGA, Ryon; MONTEIRO, Carlos. Planejamento estratégico sistêmico para instituições de ensino. São Paulo: Hoper, 2005.

BM\&FBOVESPA. A nova bolsa. Como e por que tornar-se uma companhia aberta. Utilizando o mercado de capitais para crescer. São Paulo: BM\&FBOVESPA, outubro de 2009. Disponível em: <http://www.bmfbovespa.com.br/pdf/guiaaber.pdf>. Acesso em: 1 set. 2014.

CARBONARI NETTO, Antônio. Anhanguera vai comprar mais 25 faculdades. Jornal Gazeta Mercantil. São Paulo, 26 de junho de 2008. Disponível em: <http://www.anup.com.br/noticia_detalhe.php?not_id=4152>. Acesso em: 28 ago. 2012.

CARBONARI NETTO, Antônio. Casas Bahia da educação, com orgulho. 04/09/2008(a). Disponível em: <http://exame.abril.com.br/revista-exame-pme/edicoes/0015/noticias/casasbahia-da-educacao-com-orgulho-m0167054>. Acesso em: 27 jul. 2013.

CARBONARI NETTO, Antônio. [et al.]. A Anhanguera e o processo de aprendizagem e ensino. Porto Alegre: ICDEP, 2012.

CARBONARI NETTO, Antônio. Entrevista - realizada no dia 10 de setembro de 2014.

CARBONARI, Maria Elisa Ehrhardt; DEMO, Pedro. A cultura da Anhanguera

Educacional: as crenças e valores, o bom professor, a pesquisa e a avaliação institucional como instrumento de melhoria de qualidade. Valinhos: Anhanguera Publicações, 2009.

CHAVES, Vera Lucia Jacob. Expansão e privatização/ mercantilização do ensino superior brasileiro: a formação dos oligopólios. Educação e Sociedade, Campinas: CEDES, v. 31, n. 111, p. 481-500, abr.-jun. 2010. Disponível em: <http://www.scielo.br/pdf/es/v31n111/v31n 111a10.pdf>. Acesso em: 20 fev. 2012.

CM Consultoria. Antes de Kroton, Anhanguera negociou com Estácio. 24/04/2013.

Disponível em: <http://www.cmconsultoria.com.br/vercmnews.php?codigo=65747>. Acesso em: 27 maio 2013. 
CM Consultoria. Fusões e aquisições no ensino superior - panorama 2007-2014.

Marília/SP, 2014. Disponível em:

<http://www.cmconsultoria.com.br/arquivos/GraficoAquisicoesIES.pdf >. Acesso em: 31 jul. 2014.

COLOMBO, Sonia Simões [et al.]. Gestão educacional: uma nova visão. Porto Alegre: Artmed, 2004.

CVM. Comissão de Valores Mobiliários. Bolsa de valores, mercadorias e futuros. Agosto, 2008. Disponível em: <http://www.cvm.gov.br/port/protinv/caderno9-05.pdf>. Acesso em: 8 maio 2014.

ETHOS. Instituto de responsabilidade Social. A educação dos negócios e os negócios da educação. São Paulo, 26 de setembro de 2011. Disponível em:

$<$ http://institutoethos.blogspot.com.br/2011/09/educacao-dos-negocios-e-os-negociosda.html >. Acesso em: 7 set. 2014.

FERREIRA, Suely. Reformas na Educação Superior: de FHC a Dilma Rousseff (1995-2011). Linhas Críticas, Brasília, DF, n.36, p. 455-472, maio/ago., 2012. Disponível em: <http://periodicos.unb.br/index.php/linhascriticas/article/viewFile/6794/5773>. Acesso em: 22 maio 2014.

FOITINHO, Felipe. Anhanguera vira banco para reduzir inadimplência. 07/12/2012. Disponível em: <http://www.marketingnasies.com.br/2012/03/07/anhanguera-vira-bancopara-reduzir-inadimplencia/comment-page-1>. Acesso em: 27 maio 2014.

RAMANI, Maria Cristina. A influência da qualidade na atratividade de instituições de ensino superior com capital aberto. Ensaio: Avaliação Políticas Públicas em Educação, Rio de Janeiro, v. 16, n. 60, p. 437-454, jul./set., 2008.

HAUSSER, Fernando. O marketing de relacionamento. Revista marketing, p. 10-13. 01/01/2012. Disponível em: 〈http://www.revistamarketing.com.br/materia.aspx?m=946>. Acesso em: 2 set. 2014.

ISTO É DINHEIRO. Fusão Kroton e Anhanguera: Lição de negócios. 20/04/2013. Disponível em: <http://www.istoedinheiro.com.br/noticias/negocios/20130426/fusao-krotonanhanguera-licao-negocios/115531.shtml> . Acesso em: 20 maio 2013.

IBGC. Instituto Brasileiro de Governança Corporativa. Governança corporativa. Disponível em: <http://www.ibgc.org.br/inter.php?id=18161>. 10 jun. 2012.

LAS CASAS, Alexandre (Coord.). Marketing educacional: da educação infantil ao ensino superior no contexto brasileiro. São Paulo: Saint Paul, 2008.

AUTONE, Silvana. Educação para as massas. Revista Exame. 27/07/2007. Disponível em: $<$ http://exame.abril.com.br/revista-exame/edicoes/0898/noticias/educacao-para-as-massasm0134446>. Acesso em: 10 maio 2014. 
MEIO \& MENSAGEM. Anhanguera amplia investimento no marketing. 6 de abril de 2011. Disponível em:

<http://www.meioemensagem.com.br/home/marketing/noticias/2011/04/06/20110406Anhan guera_amplia_investimento_no_marketing.html>. Acesso em: 8 set. 2014.

OLIVEIRA, Romualdo Portela. A transformação da educação em mercadoria no Brasil. Educação e Sociedade, Campinas, v. 30, n. 108, p. 739-760, out., 2009. Disponível em: <http://www.cedes.unicamp.br>. Acesso em 10 set. 2014.

PEQUENO, Alex de Oliveira; MORAIS, Rogério Santos. A escola vai à bolsa: IES privadas profissionalizam a gestão, aderem aos níveis diferenciados de governança corporativa e promovem abertura de capital na Bovespa. Anuário da Produção de Iniciação Científica Discente, v. 13, n. 17, p. 231-22, 2010. Disponível em: <http://sare.anhanguera.com/index.php/anuic/article/view/2971/1082>. Acesso em: 13 set. 2014.

POLIZEL, Caio; STEINBERG, Herbert. Governança Corporativa na educação superior: casos práticos de instituições privadas (com e sem fins lucrativos). São Paulo: Saraiva, 2013.

RODRIGUES, José. Os empresários e a educação superior. Campinas: Autores Associados, 2007.

STEPHAN, Paulo. Amostra de estudo que define perfil do estudante universitário da classe C. In: COLOMBO, Sonia Simões; RODRIGUES, Gabriel Mario e Col. Desafios da gestão universitária contemporânea. Porto Alegre: Artmed, 2011.

SETTI, Rennan. Executivo troca Google por Anhanguera. 17/09/2010. Disponível em: <http://www.cmconsultoria.com.br/vercmnews.php?codigo=47196>. Acesso em: 15 abr. 2013.

SILVA, Salete. Um jogo para profissionais. Revista Ensino Superior, São Paulo, v. 14, n. 163, p. 28-33, abr., 2012.

VEIGA, Humberto. O que é ipo? 26/10/2007. Disponível em: <http://www.betoveiga.com/log/index.php/2007/10/o-que-ipo>. Acesso em: 23 ago. 2012.

\footnotetext{
ii $\mathrm{O}$ texto originalmente faz parte do capítulo 3 da Tese de Doutorado intitulada: Grandes oligopólios da educação superior e a gestão do Grupo Anhanguera Educacional (2007-2012) de Claudia Mara Stapani Ruas, apresentada e defendida em 11 de março de 2015, na Universidade Católica Dom Bosco, Campo Grande/MS.
} 